\title{
Affirmative Action and the Utilization of Minority- and Women-Owned Businesses in Highway Procurement
}

\author{
Justin Marion $^{1}$ \\ University of California, Santa Cruz
}

February 2009

\begin{abstract}
The Federal Highway Administration (FHWA) mandates the use of affirmative action for minority- and women-owned firms by states in awarding federally funded road construction projects. In this paper, I document the variation of affirmative action across states over the history of the FHWA program, and I provide evidence regarding the effectiveness of affirmative action at increasing purchases from disadvantaged business enterprises (DBEs). DBE goals are in general effective at increasing purchases from firms owned by minorities, yet have little effect on women-owned enterprises. The effect of DBE goals are stronger when they are more likely to be binding and in states with an apparently stricter enforcement regime. Affirmative action also varies across projects within a state. Using data from California state highway procurement, and an instrumental variables approach to obtain exogenous variation in a project's DBE goal, I find that raising the affirmative action goal on a particular project by 10 percentage points increases the fraction of the contract subcontracted from DBEs by 5.4 percentage points.
\end{abstract}

\footnotetext{
${ }^{1}$ Email: marion@ucsc.edu. I appreciate the helpful comments of two anonymous referees, Rob Fairlie and participants at the 2007 WEAI Annual Conference in Seattle. Parita Suaphan provided research assistance. Funding from the UC Institute for Labor and Employment and UNC Kenan Flagler Institute is gratefully acknowledged.
} 


\section{Introduction}

Affirmative action programs in public procurement are among the more important government programs intended to advance self employment opportunities for minorities and women. In 2002, 6.75 percent of federal procurement dollars were awarded to disadvantaged business enterprises through the Small Business Administration, and preferential treatment for minority firms is a common feature of many state and local government agencies. Recent court decisions and state measures have reduced the scope of, and in some settings eliminated, affirmative action programs based on race or gender, which has given renewed importance to understanding the role of affirmative action in the success of self-employed minorities and women.

The use of affirmative action is particularly widespread in the highway procurement industry. Since the late seventies and early eighties, most states have employed affirmative action to award contracts to minority owned firms, and since 1982 the Federal Highway Administration has required states use affirmative action in awarding projects using federal funds. In 1998, states awarded $\$ 14.6$ billion of construction and repair contracts using federal funds, of which $\$ 1.9$ billion was awarded to firms owned by minorities and women. As Blanchflower and Wainright (2005) note, in the intervening years states have increasingly been able to use race-neutral measures to meet goals, which has had an adverse effect on utilization of minority-owned firms. Understanding the effects of affirmative action in this industry is made important by the significance of the public sector. According to the 2002 Census of Industries, 72.6 percent of the revenue earned by firms in the highway, street, and bridge construction industry was for government owned projects. As a result, changes in public procurement policy will have a strong effect on firms in the highway construction industry.

Despite the importance of affirmative action in this industry, our understanding of the effects of these programs is limited. States generally use percentage goals for the participation of minority-owned subcontractors by prime contractors. Past research has established the response of Disadvantaged Business Enterprise (DBE) utilization to large episodic changes in affirmative action, such as the 
elimination by certain states or cities of affirmative action programs (see for instance Blanchflower and Wainright, 2005). However, little evidence exists regarding the intensive margin of affirmative action in public procurement. That is, as participation goals are raised or lowered, what is the response of the utilization of DBEs generally, and minority- and women-owned firms specifically?

Higher DBE goals do not necessarily raise the utilization of firms owned by minorities and women for two reasons. First, the DBE goal may not be binding, in which case the marginal effect of small changes to the goal would be zero. Second, goals for the utilization of DBEs are often not perfectly enforced. For instance, a contractor facing a requirement to subcontract a fraction of a contract to DBEs can skirt this requirement by documenting a "good faith effort" to employ firms owned by minorities and women.

The goal of this paper is to provide new evidence regarding the effectiveness of affirmative action programs in highway procurement at increasing purchases from firms owned by minorities and women. Two sources of variation are employed to answer this question. The first is variation in DBE goals across states over time, and the second is variation across projects within a state. I begin by examining state level data regarding affirmative action goals and DBE utilization over the entire history of the Federal Highway Administration's affirmative action program. I utilize changes in affirmative action goals over time within states to identify the effect of affirmative action intensity on the level of DBE purchases. I find that increasing goals for the utilization of DBE goals substantially raise the utilization of minorityowned business enterprises. In the early years of the program, when MBE goals and goals for the utilization of women-owned business enterprises (WBEs) were set separately, a ten percentage point increase in the MBE goal led to a 4.5 percentage point increase in MBE utilization. After 1988, when only a combined DBE goal was set, a ten percentage point increase in the DBE goal led to a 3.5 percentage point increase in utilization. This effect is stronger in states where goals are more strictly enforced, and where goals are likely to be binding. Affirmative action is less successful in raising the utilization of WBEs. Increases in DBE goals are not successful at raising WBE participation, and increases in MBE goals in the early years of the sample are in fact associated with less WBE utilization. I 
find evidence suggesting that stricter enforcement of MBE goals enhances this effect, suggesting that departments of transportation may have faced resource constraints.

Next, I focus on variation in participation goals and utilization across projects within a particular state. I use data from California Department of Transportation (Caltrans) highway construction projects, where the state sets a DBE participation goal separately for each project. Variation in this goal is endogenously related to DBE utilization, since the goal is set based on the availability of DBEs in the neighborhood of the project, the extent of subcontracting opportunities on the project, and on the extent to which DBEs are likely to be utilized through race-neutral measures. To overcome this endogeneity bias, I utilize an instrumental variables approach, where I instrument for the DBE participation goal on a project using the average goal used during the year on projects in distant parts of the state. This instrument should capture policy variation that is unrelated to the characteristics of the project or the local supply of DBEs. The results suggest that increasing the minority participation goal by 10 percentage points raises DBE utilization by 5.4 percentage points as a fraction of contract value, and this is higher than the estimate obtained using OLS.

This paper proceeds as follows. Section 2 provides a review of the literature regarding the effect of affirmative action on minority utilization and self-employment. Section 3 provides background information on the affirmative action programs of the Federal Highway Administration and Caltrans. Section 4 describes the data that will be used; section 5 discusses the effect of affirmative action on purchases from minority firms, and section 6 concludes.

\section{Literature Review}

This paper examines the impact affirmative action in procurement has on the utilization of DBEs. As noted in a review by Holzer and Neumark (2000), evidence regarding this question in the literature is fairly sparse. The approach taken here is to examine variation in the intensity of the use of affirmative action. This stands in contrast to prior work in this area, which tends to focus on the effect on purchases from large discrete changes to affirmative action programs, such as program eliminations or adoptions. 
Blanchflower and Wainwright (2005) provide evidence on the change in utilization in several cities and counties where local affirmative action programs in procurement were halted. They also consider cases where affirmative action was eliminated by states in their state highway procurement programs specifically, making their study particularly relevant for this paper. Myers and Chan (1996) consider New Jersey contracting before and after the implementation of contract set-asides for minority- and female-owned firms. In general, the results suggest that eliminating affirmative action has a large adverse effect on purchases from minority firms, and conversely implementing affirmative action significantly improves purchases from minority firms.

Examining the timing of changes in DBE utilization surrounding the elimination or adoption of affirmative action can be a useful way to obtain exogenous variation in affirmative action, since the timing of the policy change is discontinuous while the underlying forces driving the policy change are likely to be continuous. However, much of the variation in affirmative action is in the degree of intensity of program application, and this warrants separate study since the effect on DBEs of eliminating affirmative action is potentially different from marginal changes in existing programs.

Greater purchases from minority-owned firms through affirmative action are not necessarily a positive factor in their success. Bates and Williams (1996) examine data from the Characteristics of Business Owners, utilizing a question in this survey that asks responding firms the revenues they derive from selling to the government. They find that minority business owners who rely heavily on government contracts are more likely to fail between 1987 and 1991. Blanchflower and Wainwright (1995) utilize data from the Current Population Survey to examine whether self-employment rates among minorities and women were lower after federal affirmative action programs were weakened by the case of City of Richmond v. J.A. Croson Co. In this case, the Supreme Court ruled that race-conscious programs must meet strict scrutiny requirements establishing a compelling need for the program and that the program is narrowly tailored. They find that self-employment rates among minorities and women were not significantly different post-Croson, despite the fact that many local affirmative action programs ended 
during this time. Chay and Fairlie (1998) examine cities' adoption of affirmative action programs in procurement, finding that Black self-employment rates rose dramatically in adopting cities.

Compared to the literature regarding procurement, a somewhat richer literature has examined the effects of affirmative action in employment. Leonard (1985) finds that federal contractors' affirmative action goals are associated with higher employment of minorities, despite the fact that employment goals are less strictly enforced than quotas. This study falls within a branch of the literature utilizing the fact that government contractors often face different affirmative action policies than firms not selling to the government. Heckman and Wolpin (1976), Leonard (1984), and Rodgers and Spriggs (1996) all study employment at contractors versus non-contractors to evaluate the employment effects of affirmative action, often finding mixed results. More recent studies have moved away from using contractor status as a source of variation in affirmative action across firms. McCrary (2007) examines the effects of courtordered hiring quotas in police departments, and Holzer and Neumark (2000b) find that affirmative action increases the hiring and training of minority workers. Myers (2007) uses California's Proposition 209 to evaluate the effects of affirmative action in the labor market, finding significant adverse employment effects for minorities and women following the elimination of affirmative action.

\section{Background: Affirmative Action in Highway Procurement}

\subsection{Affirmative Action and the Federal Highway Administration}

Beginning in 1982, the U.S. Department of Transportation required states to implement affirmative action programs for minorities in the awarding of road construction contracts that are funded with federal aid. States were required to award at least 10 percent of the value of its contracts to small businesses owned and operated by minorities. States could petition to set a goal for minority participation of less than 10 percent. In 1988, the program was extended to include women-owned business enterprises (WBEs), so that states could satisfy the 10 percent requirement by awarding contract dollars to firms owned by women in addition to purchases from minority-owned business enterprises (MBEs). It was common prior to 1988 for states to set a separate goal for the participation of WBEs. In any case, 
subcontracts with DBEs, and not just the value of prime contracts awarded to DBEs, are counted toward meeting the DBE goal.

\subsection{Affirmative Action at Caltrans}

The California Department of Transportation (Caltrans) sets a statewide goal for the participation of DBEs on state highway construction, which it meets by setting a DBE subcontractor participation goal on a project-by-project basis. To qualify as a DBE, a firm must meet two requirements: an ownership requirement that at least 51 percent of a business must be owned by the group for which the goal applies, and an operations requirement that the minority or female owners be involved in the day-to-day operation of the business.

Firms bidding for construction contracts must supply a list of the subcontractors to be used in the completion of the project. A qualifying bid either meets the participation goal stipulated in the contract, or documents a good faith effort to locate DBEs in the event that the participation goal is not met. ${ }^{2,3}$ Bids are often rejected for failing one of these two tests. From May 1996 until the end of 2002, 36 low bids were rejected on this basis.

The participation goals are allowed to vary across contracts, depending on the local DBE supply of firms able to provide the work required on the contract. Furthermore, these goals may be used less intensively in areas of the state with an already high level of DBE utilization.

Voters in California passed a statewide referendum, Proposition 209, in June 1996 that was intended to eliminate the consideration of race and gender in state contracting, education, and employment. This ballot initiative affected only those projects using only state funds, as projects using federal funds were required to maintain the affirmative action policy mandated by the U.S. Department of Transportation.

\footnotetext{
${ }^{2}$ Prior to a rule change in 2000 , even if the contractor was a DBE, it still needed to meet the subcontractor participation goal.

${ }^{3}$ To meet the good faith effort requirement, the bidder must document its efforts to locate DBE subcontractors such as advertisements placed in trade magazines and minority focused papers. Next it must show how it attempted to solicit bids directly from DBE subcontractors. If a DBE firm was located, the bidding firm must show what portions of the contract were made available, and if the DBE was not able to perform the work, what efforts were made to assist the DBE in obtaining bonding, lines of credit, or technical assistance in performing the work. If a lack of equipment or materials prevented the DBE from performing the work, efforts must also have been made by the bidder to remedy this deficiency.
} 


\section{$4 \quad$ Data}

\subsection{State DBE Utilization}

As already discussed, states set DBE participation goals for purchases of road construction projects. In addition, state departments of transportation must track commitments and subsequent actual awards made to DBEs by prime contractors and report this information to the Federal Highway Administration (FHWA). Awards can differ from commitments due to changes in project scope or if DBE subcontractors must be replaced. Consider a firm who won a road construction contract with a DBE subcontracting goal imposed by the state. If the portions of the project originally scheduled to be subcontracted to DBEs turned out to be less expensive to build than originally estimated, then the committed amount could be greater than the actual DBE award. Also, if a DBE is unable to perform the work on a contract after being hired, it is not always be replaced by a substitute. As with fulfilling the good faith effort at the time of bid submission, the prime contractor can avoid replacing the subcontractor with another DBE if it can show that a substitute DBE is unavailable. The gap between commitment and awards may therefore arise for legitimate reasons. However, states may differ in their enforcement of the documentation of the good faith effort to find replacement DBEs, so the gap between awards and commitments may reflect imperfect enforcement of affirmative action.

The FHWA uses the award information to evaluate the satisfaction of a state's DBE goal. In the first portion of the paper, I will use these data for the years 1983-1999. Prior to 1988, awards made to womenowned businesses were not used towards satisfaction of the DBE goal. However all states set separate WBE goals during this time and recorded commitments and awards made to WBEs. After 1987, the MBE and WBE figures were not separately reported, and only total DBE goals were recorded.

\subsection{California Highway Procurement Auctions and Firms}

The project-level data in this study consists of information for highway construction auctions conducted by the California Department of Transportation between May 1996 and December 2002. For each contract up for bid, a set of information describing the project is given, including the road and 
county where the work will take place; a short description of the nature of work to be completed; the estimated number of working days to complete the project; and an engineer's estimate of the cost of completing the project. The engineer's estimate is formulated by Caltrans and reflects project-specific factors incorporating past bids on similar projects. The federal-aid status of the contract is given as well as the DBE participation goal that applies to that project. For every general contractor submitting a bid, the value of the bid and a list of first tier subcontractors are given. ${ }^{4} \mathrm{~A}$ unique identifier is assigned to each firm, so it is possible to track firms across contracts. For a subset of 1293 of these contracts, I was able to obtain the utilization of DBE subcontractors, and the final payments by Caltrans to the prime contractor. ${ }^{5}$

\section{$5 \quad$ Affirmative Action and DBE Utilization}

\subsection{Variation across states}

In this section, I consider how affirmative action affects the utilization of minority firms by examining variation in the intensity of affirmative action programs across states. I begin by describing state affirmative action goals and DBE utilization. States are required to set a minimum 10 percent goal for the utilization of disadvantaged business enterprises, and while states tend to cluster at this minimum standard, there remains significant variation in the intensity of affirmative action across states. Table 1 displays summary statistics for state programs. The average state awards $\$ 308.5$ million (in 1999 dollars) in federal-aid contracts per year, 12.6 percent of which is awarded to either MBEs or WBEs. States set the minimum 10 percent DBE goal for 73.8 percent of the state-years. The average goal that is set is 11.65 percent, and, reflecting the clustering of states at 10 percent, the standard deviation of the DBE goal is relatively small at 2.58 percent.

\footnotetext{
${ }^{4}$ A first tier subcontractor performs at least $\$ 10,000$ or half of a percent of the contract, whichever is greater.

${ }^{5}$ As already mentioned, a policy change in 2000 allowed a DBE prime contractor to count herself toward meeting the DBE goal on a project. For the purposes of consistency across years, I drop the 29 cases in which this occurred in the estimation.
} 
The clustering of states at the minimum goal suggests that the desired goal for most states is less than 10 percent. Despite this, states in general seem compliant with the goals they set out. States award contracts in excess of the DBE goal in 69 percent of the state-years.

Table 1 also presents evidence regarding the evolution of state affirmative action programs over time by splitting the sample between three time periods: 1983-1987, 1988-1993, and 1994-1999. The overall DBE goal has changed only modestly between these three periods. From 1983-1987, the average goal was set at 12.01 percent, and declined to 11.43 percent in the later period. This stability in the DBE goal masks two important trends in states' affirmative action programs. First is the importance of womenowned subcontractors. Prior to 1988, states set separate goals for the utilization of minority owned firms and firms owned by women, and these goals were met separately. During this time, the average MBE goal was 9.9 percent, nearly five times the average WBE goal of 2.1 percent. As a result utilization was also tilted significantly towards MBEs, as these firms received 11.0 percent of contracting dollars while WBEs were awarded 3.1 percent. After 1988, states only set a common DBE goal, which could be satisfied by contracting with either MBEs or WBEs. The utilization of WBEs subsequently rose dramatically, as these firms received 5.0 percent of contracts from 1988 through 1993 and 5.8 percent of contracts between 1993 and 1999. The latter figure is nearly on par with MBE utilization, which was 7.0 percent during this time. The second important trend during this time was the decline in states' compliance with the affirmative action goals set. While approximately 75 percent of state-years meet the goal prior to 1994, between 1994 and 1999, only 59 percent of state-years are in compliance.

The last row of Table 1 provides information regarding the frequency of changes in DBE goals. In the early years of the program, states changed their goals frequently, perhaps reflecting a fine tuning of a relatively new program. This period witnessed 88 changes in the DBE goal. After 1988, states altered DBE goals less frequently, as there were 37 state-month changes in the DBE goal. ${ }^{6}$ The 125 changes in

\footnotetext{
${ }^{6}$ It is important to note that this does not include 15 changes occurring in 1988, due to the differences in how I define the total DBE goal in the pre- and post-1988 periods.
} 
the DBE goal during the entire sample period included 92 increases averaging 1.9 percentage points and 33 decreases averaging 2.1 percentage points.

Figure 1 displays the trends in the contracting goals and the utilization of MBEs and DBEs over time. As previously described, these programs experienced a significant decline in MBE utilization and a significant increase in WBE utilization over time, while the overall utilization of DBEs has remained relatively stable. As mentioned in Section 4.1, the gap between the commitments and actual awards to DBEs may reflect a compliance issue. As we see in Figure 1, the gap between the actual contract awards and the commitments made to DBEs grows noticeably after 1991.

In Table 2, each state's goal is reported for three years: 1984, 1991, and 1999. The goal reported for 1984 is the sum of the state's MBE and WBE goal. Compared to later years, the DBE goal in 1984 is more likely to fall below 10 percent, however for many states the combined goal is actually higher than in later years. By 1991, during the time when WBE utilization counted toward satisfying the DBE goal, there is significant bunching at the 10 percent minimum, yet no state chose a DBE goal of less than 10 percent. Also, examining the goal, one sees that it tends to be set higher in states with high minority populations. For instance, California and New York have two of the highest DBE goals in 1984 and 1991. Both of these states, though, had substantially reduced their DBE goal by 1999.

This serves to illustrate the strategy that will be taken in this section to identify the effects of DBE goals on DBE utilization. I am interested in estimating the relationship between the DBE goal and DBE utilization:

$$
U_{i t}=\beta_{0}+\beta_{1} g_{i t}+B X_{i t}+\gamma_{i}+\varphi_{t}+\varepsilon_{i t}
$$

where $U_{i t}$ is the utilization of DBEs as a percentage of the contract awards in state $i$ in time period $t, g_{i t}$ is the DBE goal, and $\varphi_{t}$ is a year-specific shock affecting all states. The vector of covariates $X_{i t}$ includes state GSP, the state unemployment rate, the party of the state governor, and the fraction of the state 
population comprised by minority residents. To account for unobserved state effects $\gamma_{i}$, I will estimate a first-differenced version of $(1)^{7}$ :

$$
\Delta U_{i t}=\beta_{1} \Delta g_{i t}+B \Delta X_{i t}+\rho_{t}+\eta_{i t}
$$

Therefore, the coefficient $\beta_{1}$ will be identified using within state changes in the DBE goal and their contemporaneous relationship with changes in utilization. The advantage of the first-differenced specification is that factors affecting DBE supply and demand are likely to evolve slowly over time, while DBE goals change only infrequently. While this may not hold due to higher frequency events, such as business cycle fluctuations, the validity of this approach can be further investigated by considering specifications with and without the inclusions of controls such as state GSP and the unemployment rate.

The estimation will be conducted separately for the periods before and after 1988, the first year that a combined goal was set for DBE utilization rather than separate goals for MBEs and WBEs. In the pre1988 period, results will be presented first using the sum of the MBE and WBE goals as the dependent variable and subsequently for these goals individually. The estimation will also be conducted for the total utilization of DBEs, and separately for MBE and WBE utilization.

The effect of DBE goals may depend on state characteristics such as enforcement. I will allow the coefficient $\beta_{1}$ to depend on the gap between commitment and awards experienced in the state during the time period covered by the specification. Year-to-year "bad luck" should be averaged out, and the resulting measure should capture the degree to which states enforce good faith effort requirements.

In addition to enforcement, the coefficient $\beta_{1}$ may depend on how binding the goal is in a particular state. If the state is easily meeting its goal, for instance, then small changes in the goal should have little effect. ${ }^{8}$ To consider this possibility, I will also estimate $\beta_{1}$ separately for cases where awards in the prior period were relatively close to the stated goal and for cases where prior awards were relatively far from the state's DBE goal.

\footnotetext{
${ }^{7}$ Equation (1) could be estimated directly using state fixed effects, however this may be undesirable in this setting due to serial correlation in the error term.

${ }^{8}$ This is not necessarily true if a state targets the increased goal toward projects or areas that were previously experiencing low DBE utilization.
} 
In Tables 3a-3c, I present estimates of equation (2) separately for the utilization of DBEs, MBEs, and WBEs, respectively. I first consider the utilization of DBEs. In columns (1)-(5), I present the results for the 1983-1987 time period. Changes in the combined DBE goal do not correlate with changes in DBE utilization during this period. With the full set of controls, the coefficient on the DBE goal is just 0.02, though it is worth noting that this is not estimated with a tremendous amount of precision. In the specifications shown in columns (4) and (5), the effect of changes in the MBE and WBE goals are estimated separately. These results also suffer from a lack of precision, as neither the coefficients on the MBE nor WBE goals enter significantly. The WBE goal has a substantially positive coefficient estimate of 0.616, while the MBE goal has a substantially negative coefficient value of -0.306 .

In columns (6)-(8), I present the results for the later period, 1988-1999. In contrast to the earlier period, greater DBE goals are associated with greater DBE utilization. A ten percentage point increase in the DBE goal is associated with a 3.96 percentage point increase in DBE utilization. It is worth noting at this point that the inclusion of additional control variables alters little the estimated coefficient, which here is 0.405 in the sparser specification without controls. The estimates of the coefficients on the DBE, MBE, and WBE goals are similarly affected little in the pre-1988 specifications.

While DBE goals have a strong impact on DBE utilization in the later period, an interesting pattern emerges when this effect is allowed to depend on a measure of affirmative action enforcement, the average ratio between awards and commitments within a state. In the specification shown in column (8) of Table 3a, I include an interaction between the DBE goal and this ratio. We see that the interaction term is positive and significant at 1.212 , while the direct effect of the DBE goal is estimated to be -0.567 . To understand the value of these coefficients, consider states with very low and very high ratios between DBE awards and commitments. The $10^{\text {th }}$ percentile of this measure is 0.697 , while the $90^{\text {th }}$ percentile is 1.034. A "strong enforcement state", one in the $90^{\text {th }}$ percentile of the award-commit ratio distribution, is estimated to have a DBE goals coefficient of 0.685 ( $\mathrm{p}$-value $=0.006$ ). On the other hand, the coefficient on DBE goals in the $10^{\text {th }}$ percentile state is only $0.277(\mathrm{p}$-value $=0.09)$. 
The effect of enforcement in the early period is not as clear. The interaction between the awardcommit ratio and the DBE goal is not statistically significant. Interestingly, the signs are the opposite from the later period - states with greater "enforcement" see a lower effect of DBE goals. The perverse effect of enforcement, along with the lack of a statistically undetectable effect of DBE goals, suggests that caution should be taken when drawing inference regarding the early years of the program. Prior to the more mature later years of the program, states may be unsure of how high to set MBE and WBE goals. The frequency of states' adjustments to goals during this time is suggestive of this. Goals that are set too high to begin with may be subsequently lowered even while actual DBE utilization is on the rise. Furthermore, there may be a period of initial adjustment as the entry of minority- and women-owned firms is prompted. This could affect the award-commit ratio, since new firms may be more likely to be replaced on a project.

The effects of affirmative action could differ significantly for minority- and women-owned businesses. In Table 3b, I present results for specifications using the proportion of contract dollars going to MBEs. Again, I separate the estimation for the pre- and post-1988 time periods. In the early years of the sample, more intensive use of affirmative action leads to greater utilization of minority-owned firms. Each ten percentage point increase in the DBE goal leads to a 5.2 percentage point increase in MBE utilization. As with DBE utilization overall, the inclusion of controls has little effect on the estimated coefficients. I next include the MBE and WBE goals into the specification of MBE utilization separately, as shown in columns (4) and (5). As should be expected, MBE goals increase the utilization of MBEs - a ten percentage point increase in MBE goals is associated with a 4.5 percentage point increase in MBE utilization. Interestingly, WBE goals are also associated with greater MBE utilization. This effect, while not statistically significant in the full specification, is in fact greater than the direct effect of MBE goals. A portion of the positive effect of WBE goals may be driven by firms owned by minority women. Increases in WBE goals may also reflect a general ramping up of a state's affirmative action program, where enforcement efforts increase along with goals. 
Raising DBE goals during the post-1988 period also leads to greater MBE utilization. A ten percentage point increase in the DBE goal is associated with a 3.5 percentage point increase in MBE utilization during this time. As with DBE utilization as a whole, goals are more effective in states with a higher ratio of awards to commitments. The tenth percentile of the award/commit ratio is 0.752 and the $90^{\text {th }}$ is 1.071 . The coefficient on the DBE goal in the low enforcement states is 0.308 ( $\mathrm{p}$-value $\left.=0.019\right)$ while the DBE goal coefficient in the high enforcement states is 0.634 (p-value $=0.009)$. This stands in contrast to the pre-1988 period, where the award-commitment ratio does not have a statistically detectable effect on the DBE goal coefficient. It is worth noting, however, that the lack of statistical significance is not due to the magnitude of the estimated coefficients, as they are at least as large as in the post-1988 period. Furthermore, the coefficients are of different signs during the early period. As with the enforcement results for DBEs more generally, this may reflect the evolving nature of states' programs early in the period.

Finally, in Table 3c, I consider the utilization of women-owned businesses. The DBE goal in the early years of the affirmative action program is estimated to be negatively correlated with WBE utilization. A ten percentage point increase in the combined DBE goal during this period is associated with a 5.0 percentage point decrease in WBE utilization. In columns (4) and (5) of this table, I show the results from estimating the effect of MBE and WBE goals separately. These results indicate that WBE goals bear virtually no relationship with WBE utilization, with an estimated coefficient of -0.024 . The negative correlation between DBE goals and WBE utilization seems driven entirely by the effect of MBE goals. A ten percentage point increase in MBE goals is associated with a 7.6 percentage point decrease in WBE utilization.

In the more mature years of the program, the relationship between goals and WBE utilization is no longer present. In columns (7)-(9) of Table 3c I present the results for 1988-1999. Changes in DBE goals are unrelated to changes in WBE utilization. The estimates are precise as well. I estimate a coefficient on the DBE goal variable of 0.043 , and the standard error of this estimate is 0.092 , implying that coefficient values above 0.228 are outside the 95 percent confidence interval. Furthermore, states with stronger 
enforcement regimes do not have substantially different effects of DBE goals on WBE utilization than states with weak enforcement regimes. This seems true both in the 1983-1987 years as well as the 19881999 period.

The paradoxical relationship between MBE goals and WBE utilization suggests either a substitution between MBEs and WBEs by firms, or fixed enforcement resources on the part of state departments of transportation. To investigate the latter possibility, I consider an interaction between the MBE goal and the enforcement measure, the award-commit ratio. States committing more resources to MBE enforcement may be constrained in WBE enforcement. The results of this estimation are presented in column (6) of Table 3c. These results suggest that the direct effect of MBE goals is positive. However, the effect of MBE goals on WBE utilization is significantly lower in states where MBE commitments are realized in awards at a higher rate.

\section{Binding versus non-binding goals}

DBE goals represent a constraint on subcontracting decisions within a state. The effect of a change in the DBE goal is therefore likely to differ depending on the extent that this change alters the degree to which the constraint is binding. In states whose DBE utilization is substantially exceeding their DBE goal, an increase in the DBE goal is less binding. A similar line of logic applies to states whose DBE utilization is substantially exceeded by the DBE goal.

To investigate this possibility, I separate state-years based on the DBE utilization relative to the DBE goal in the prior year. In Table 4, I present the results of the effect of DBE goals on DBE utilization. In the first row, I restate the primary results shown in Tables 3a-3c. I then show similar results for stateyears where the prior year's utilization was within three percentage points of the DBE goal, and those state-years where utilization is further than three percentage points. This cutoff was chosen to encompass 80 percent of the changes in the DBE goal. Changes in "close" state-years are likely to have a larger marginal impact.

This hypothesis is confirmed in the results presented in Table 4 for the 1988-1999 years. The coefficient on the DBE goal variable is 0.59 and statistically significant in the "close" state-years but is 
only 0.31 and statistically insignificant in years unlikely to be binding. Similar results obtain in the specification of MBE utilization. In close years, the coefficient is 0.48 compared to 0.30 in less binding years. For WBE utilization, changes in DBE goals have little effect, regardless of how binding the DBE goal is. In the pre-1988 years, the combined DBE goal is ineffective at increasing DBE utilization regardless of the likelihood of a state's goal binding. However, the DBE goal is actually significantly positively related to MBE utilization in the pre-1988 years when utilization is not close to the goal. Once again, the effects of the affirmative action program differ in the early years of the program.

\subsection{Variation across projects}

While DBE goals vary considerably across states, an additional source of variation in affirmative action is across projects within a state. States often set a separate DBE goal on a project-by-project basis, which affords some discretion in targeting affirmative action to those instances where it is most effective or least costly. This discretion leads to particular problems when estimating the effect of affirmative action on DBE utilization. Goals are endogenous to DBE supply and subcontracting opportunities, and are often set lower when the base utilization of DBEs is already high.

Table 4 describes the characteristics of contracts awarded by Caltrans, split by the level of the DBE subcontracting goal used by project. The winning bid of the average federal aid project is $\$ 2.6$ million. The average DBE goal is 11.3 percent, weighted by the engineer's estimate of project cost. In other words, at least 11.3 percent of federal aid contract dollars are to be awarded to DBE subcontractors. There is a significant degree of variation in this goal across projects, as the standard deviation of the DBE goal represents 31 percent of its mean. For the average project, DBEs are hired for $\$ 358$ thousand of work, amounting to 12.6 percent of total contract dollars. The DBE goal is set higher for larger projects. The average winning bid for projects with between 10 and 20 percent participation goal is $\$ 4.1$ million, compared with $\$ 1.4$ million for projects with a DBE goal of between 1 and 10 percent and $\$ 467$ thousand for those projects where the goal is set to zero. While the DBE goal may be reflected directly in the winning bid if it raises the costs of prime contractors, independent measures of project scale such as the engineer's estimate, number of project workdays, and the number of items required for the project are all 
considerably larger when the DBE goal is higher. This may indicate that there is a fixed cost of subcontracting, which makes high DBE goals unattractive for small contracts.

Two other features of the data stand out. First, DBE subcontractors are used to a considerable extent even on projects with a DBE goal of zero, receiving subcontracts amounting to 6.4 percent of these contracts. Even so, the degree of DBE subcontracting rises substantially with the DBE goal, as utilization is 13.5 percent of projects with a goal of between 10 and 20 percent. Second, the number of utilized subcontractors increases substantially as the goal is increased. This could reflect Caltrans setting a higher goal for projects with greater subcontracting opportunities; however it is also consistent with these subcontractor goals altering the make-versus-buy decision. Marion (forthcoming) documents a substantial decline in the use of subcontractors for state funded contracts after Proposition 209, which eliminated the DBE goals for these contracts.

The primary goal of this section is to estimate the relationship between DBE utilization and the project-specific goal:

$$
U_{i}=\beta_{0}+\beta_{1} g_{i}+B X_{i}+\varepsilon_{i}
$$

where $U_{i}$ is the percentage of the contract payments that go to DBE subcontractors on project $i, g_{i}$ is the project specific goal, and $X_{i}$ is a vector of project characteristics such as scale, location, and season. For several reasons, $g_{i}$ could be correlated with the error term $\varepsilon_{\mathrm{i}}$. The goal is set higher when there are more subcontracting possibilities and when there is a large local supply of DBEs. These factors tend to bias the estimated coefficient $\beta_{1}$ upward. On the other hand, contractors can fall short of the goal by making a "good faith effort" to employ DBEs. When this is likely to occur, the state may set goals higher to offset this behavior, which would tend to bias the coefficient $\beta_{1}$ downward. Similarly, some areas of the state have a high base level of DBE utilization. In this case, the state may need to use affirmative action less intensively.

One can classify the variation in $g_{i}$ into two categories. First are project-specific factors such as location and type of work. These tend to be endogenous to DBE utilization at the project level for the 
reasons just described. The second type of variation is policy related, where shifting priorities of the state over time lead to changes in the DBE goal employed. To obtain exogenous variation in $g_{i}$, I will utilize only the second type of variation, due to statewide policy choices, which should be exogenous to unobserved project-specific factors that shift both $U_{i}$ and $g_{i}$, conditional on time trends. I will use an instrumental variables approach, where I instrument for the project-specific goal using the average goal used for projects in distant parts of the state in the same year. California is divided into 12 districts by Caltrans. Figure 2 shows a map of California, with the Caltrans districts overlaid over the counties in the state. Caltrans districts are geographically sizable. To describe the average goal in other parts of the state, I will take the average goal used in non-neighboring districts. DBE supply may be spatially correlated, but by taking the average goal in non-neighboring districts, I am considering projects that are outside the project's relevant market. From the map in Figure 2, we see that except in rare cases, the nearest border of a non-neighboring is a considerable distance away.

Even if non-neighboring districts are outside the relevant market of a project, the IV strategy will be invalid if there are factors shifting DBE supply across the entire state. These factors are likely to evolve slowly over time, so I will account for them using a quadratic time trend.

Table 5 presents the results of this estimation. In columns (1) and (2), I present OLS estimates of the relationship between DBE utilization and the project goal. The specification shown in the first column includes no controls, and the coefficient $\beta_{1}$ is estimated to be 0.398 . This indicates that a project with a DBE goal that is 10 percentage points higher is associated with 4 percentage points more of the project value being subcontracted to DBEs. Column (2) displays the specification with the full set of controls, which include measures of project scale such as the log of the engineer's estimate and project workdays, dummies for the type of work on the project, month effects, and a quadratic time trend. Interestingly, the addition of these controls changes the point estimate only slightly to 0.41 .

In columns (3) and (4) of Table 5, I present the first stage relationship between the project DBE goal and the DBE goal in non-neighboring districts. We see that a 10 percentage point increase in the goal in other parts of the state in a particular year is associated with a 3.8 percentage point increase in a project's 
goal. In Columns (5) and (6), I present the IV estimate of $\beta_{1}$, which is 0.54 regardless of whether or not controls are included in the specification. This suggests that OLS estimates actually understate the marginal effect of increasing DBE goals, and indicates that the state may use affirmative action less for projects likely to intensively use DBEs even in the absence of affirmative action.

\section{Conclusion}

This paper provides new evidence regarding the effectiveness of affirmative action in public highway construction, an understudied yet important policy. During the mature years of the program, more intensively used affirmative action at the state level significantly increases purchases from firms owned by minorities, yet has little effect on purchases from women-owned firms. Increasing the DBE goal is more effective at raising DBE utilization in states with stronger enforcement regimes and when the increased goal is likely to be binding. In the early years of the program, states change their goals often, which is likely due to initial adjustment to program parameters, perhaps to make them more appropriate for state conditions. Several odd results arise as a result - apparently stronger enforcement regimes actually have a lower DBE utilization-goal gradient, and changing the state goal has a larger effect during this time when states are easily meeting or widely missing their DBE goal. Results from this period should be treated with appropriate caution.

Project-level evidence suggests a positive relationship between utilization and goals, as a 10 percentage point increase in the DBE goal is estimated to raise the DBE share of a contract by 5.4 percentage points. This estimate is obtained using plausibly exogenous variation in the goal across projects, which captures only variation in state priorities and not project-specific factors such as local DBE supply and subcontracting opportunities.

Two caveats are worth mentioning when interpreting the results of this paper. First, a widely recognized hindrance to the effectiveness of affirmative action in procurement are "front companies," where a firm is fronted by a minority or a woman but is in fact owned by a white man. Front companies are not distinguishable from authentic minority- and women-owned firms in my data. Thus, the measure I 
provide likely overstates the increase in utilization of true disadvantaged business enterprises from raising DBE goals. Second, I do not attempt to measure the long-run effects of affirmative action policies. The existence of learning-by-doing, relational contracting, or information problems contributing to statistical discrimination would all lead to long-lasting effects of affirmative action. One such channel is the effect of affirmative action on negative stereotypes suggested by Coate and Loury (1993). Increasing the DBE goal today could have a permanent effect on DBE utilization that persists even if the goal is later reduced. 


\section{References}

Bates, Timothy and Darrell Williams. (1995) "Preferential Procurement Programs and Minority-Owned Businesses," Journal of Urban Affairs 17:1, pp. 1-17.

---- (1996) “Do Preferential Procurement Programs Benefit Minority Business?” The American Economic Review 86:2, 294-97.

Blanchflower, David G. and Jon Wainwright. (2005) "An Analysis of the Impact of Affirmative Action Programs on Self-Employment in the Construction Industry," NBER Working Paper \#11793.

Chay, Kenneth and Robert Fairlie. "Minority Business Set-Asides and Black Self-Employment," Mimeo, U. of California, Berkeley, 1998.

Coate, Stephen and Glenn C. Loury. (1993) "Will Affirmative-Action Policies Eliminate Negative Stereotypes?" The American Economic Review 83:5, pp. 1220-40.

Heckman, James J. and Kenneth I. Wolpin. (1976) "Does the Contractor Compliance Program Work? An Analysis of Chicago Data," Industrial and Labor Relations Review 29:4, p. 544-564.

Holzer, Harry and David Neumark. (2000a) “Assessing Affirmative Action,” Journal of Economic Literature 38:3, 483-568.

-----. (2000b) “What Does Affirmative Action Do?” Industrial and Labor Relations Review 53:2, p. 240-271.

Leonard, Jonathan S. (1984) "The Impact of Affirmative Action on Employment," Journal of Labor Economics 2:4, 439-463.

---- (1985) "What Are Promises Worth: The Impact of Affirmative Action Goals," Journal of Human Resources 20:1, p. 3-20.

Marion, Justin. (forthcoming) 'How Costly is Affirmative Action? Government Contracting and California's Proposition 209," Review of Economics and Statistics.

McCrary, Justin. (2007) "The Effect of Court-Ordered Hiring Quotas on the Composition and Quality of Police," The American Economic Review 97:1, p. 318-353.

Myers, Caitlin. (2007) "A Cure for Discrimination? Affirmative Action and the Case of California Proposition 209," Industrial and Labor Relations Review 60:3, p. 379-396.

Myers, Samuel and Tsze Chan. (1996) "Who Benefits from Minority Set-Asides? The Case of New Jersey," Journal of Policy Analysis and Management 15:2, pp. 202-26.

Rodgers, William M. III and William E. Spriggs. (1996) "The Effect of Federal Contractor Status on Racial Differences in Establishment-Level Employment Shares: 1979-1992," The American Economic Review 86:2, p. 290-293. 


\section{Figure 1: Average State DBE Utilization}

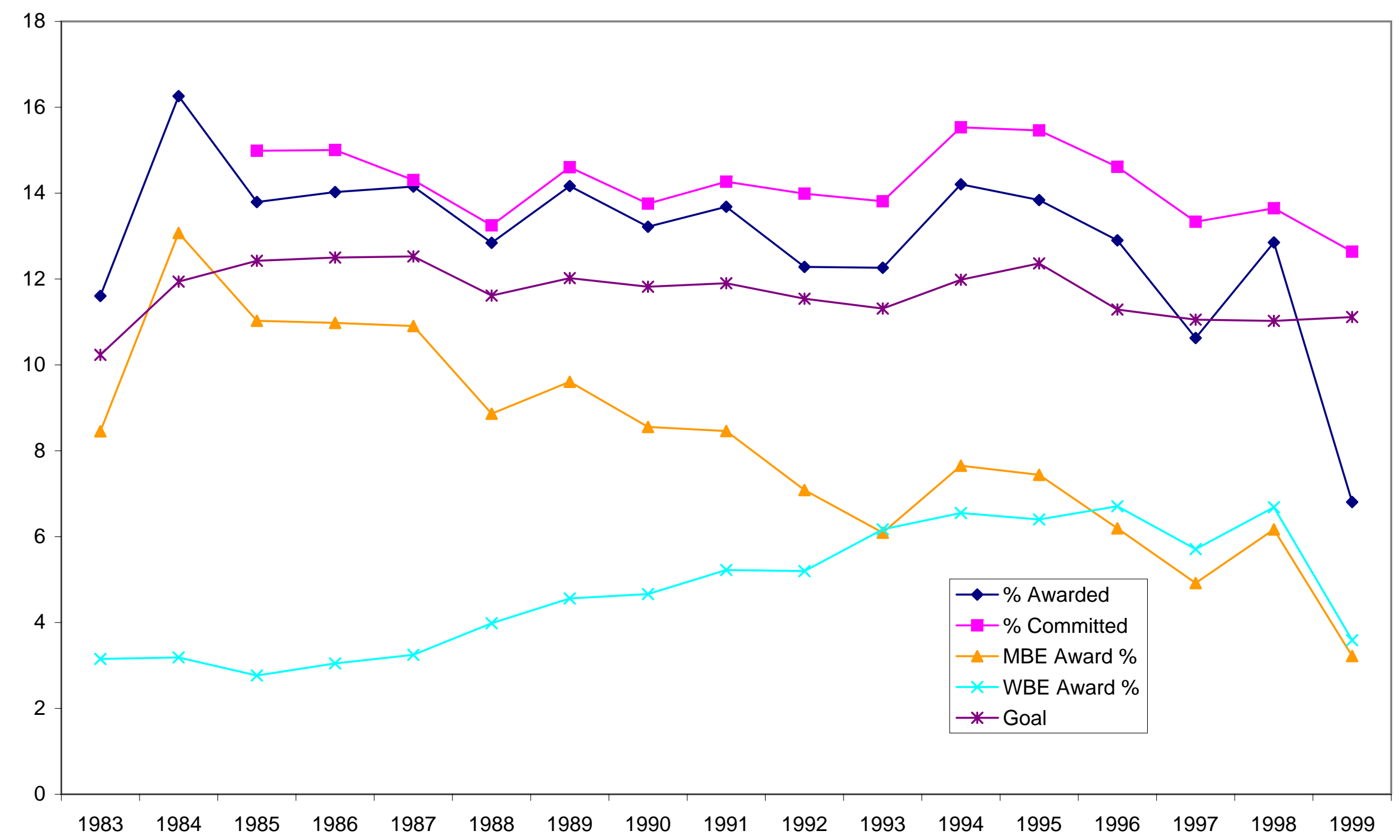


Figure 2: California Department of Transportation Districts

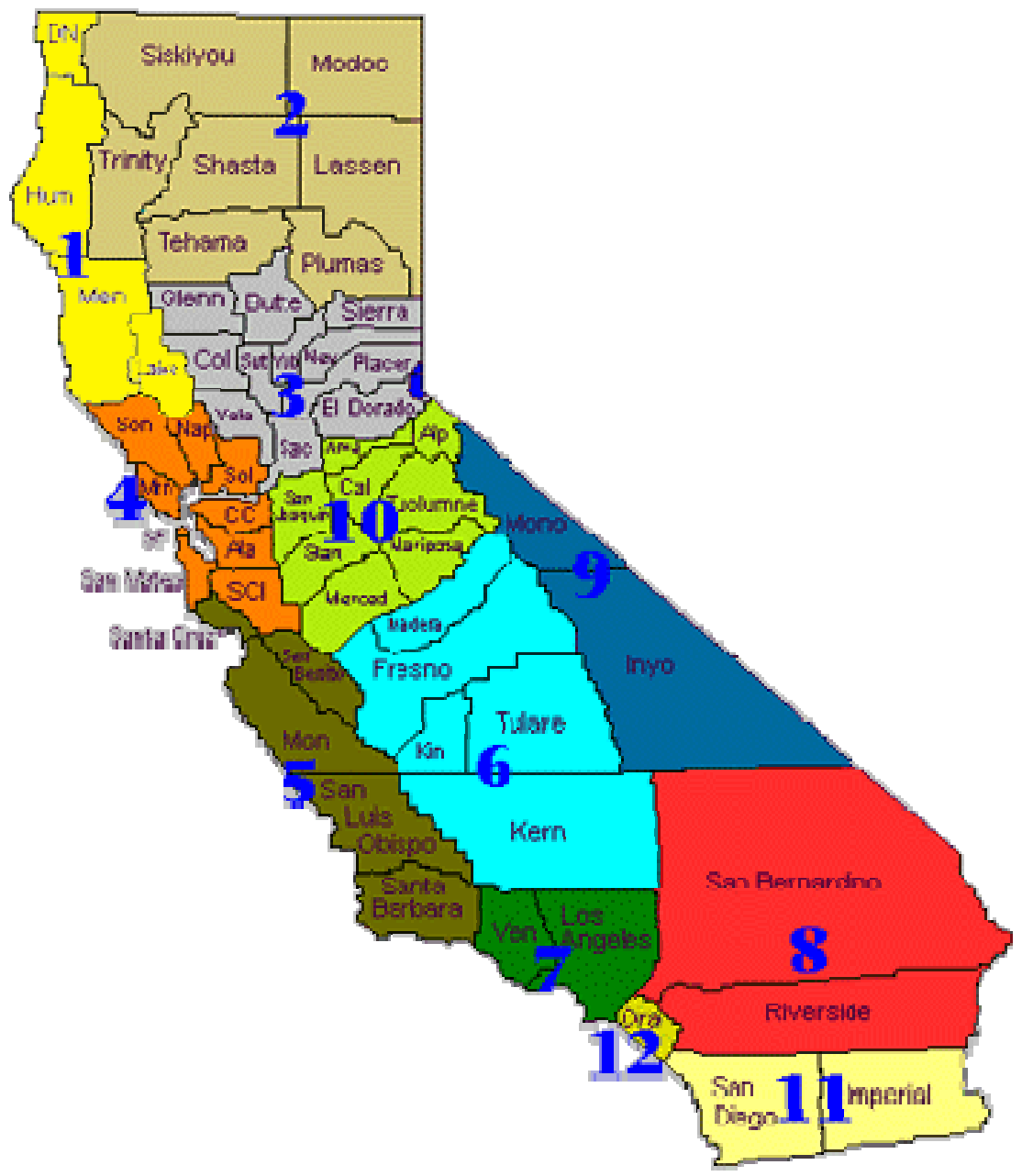




\begin{tabular}{|c|c|c|c|c|}
\hline & $\begin{array}{c}(1) \\
1983-1987\end{array}$ & $\begin{array}{c}(2) \\
1988-1993\end{array}$ & $\frac{(3)}{1994-1999}$ & $\begin{array}{c}(4) \\
\text { Total }\end{array}$ \\
\hline Total DBE Goal & $\begin{array}{c}12.01 \% \\
(2.02)\end{array}$ & $\begin{array}{c}11.68 \% \\
(3.11)\end{array}$ & $\begin{array}{c}11.43 \% \\
(2.38)\end{array}$ & $\begin{array}{c}11.65 \% \\
(2.58)\end{array}$ \\
\hline MBE Goal & $\begin{array}{l}9.94 \% \\
(1.37)\end{array}$ & & & \\
\hline WBE Goal & $\begin{array}{l}2.08 \% \\
(1.26)\end{array}$ & & & \\
\hline Value of Contracts (millions) & $\begin{array}{l}198.43 \\
(171.2)\end{array}$ & $\begin{array}{c}236.73 \\
(226.73)\end{array}$ & $\begin{array}{c}302.9 \\
(304.6)\end{array}$ & $\begin{array}{c}248.8 \\
(247.4)\end{array}$ \\
\hline MBE Awards (millions) & $\begin{array}{c}21.74 \\
(19.8) \\
{[11.0 \%]}\end{array}$ & $\begin{array}{l}18.93 \\
(25.1) \\
{[8.0 \%]}\end{array}$ & $\begin{array}{l}17.37 \\
(25.2) \\
{[5.7 \%]}\end{array}$ & $\begin{array}{c}19.21 \\
(23.75) \\
{[7.7 \%]}\end{array}$ \\
\hline MBE Commitments (millions) & & $\begin{array}{c}20.43 \\
(26.4) \\
{[8.6 \%]}\end{array}$ & $\begin{array}{c}21.07 \\
(28.8) \\
{[7.0 \%]}\end{array}$ & \\
\hline WBE Awards (millions) & $\begin{array}{c}6.09 \\
(6.8) \\
{[3.1 \%]}\end{array}$ & $\begin{array}{c}11.88 \\
(12.3) \\
{[5.0 \%]}\end{array}$ & $\begin{array}{l}17.58 \\
(18.6) \\
{[5.8 \%]}\end{array}$ & $\begin{array}{l}12.19 \\
(14.6) \\
{[4.9 \%]}\end{array}$ \\
\hline WBE Commitments (millions) & & $\begin{array}{c}12.6 \\
(12.6) \\
{[5.3 \%]}\end{array}$ & $\begin{array}{l}21.56 \\
(22.2) \\
{[7.1 \%]}\end{array}$ & \\
\hline State-years with $10 \%$ DBE Goal & $68.0 \%$ & $76.7 \%$ & $75.7 \%$ & $73.8 \%$ \\
\hline State-years attaining goal & $74.0 \%$ & $76.0 \%$ & $58.7 \%$ & $69.3 \%$ \\
\hline State-months with DBE goal change & 88 & 15 & 22 & 125 \\
\hline
\end{tabular}

Standard deviations are in parentheses. The figure in brackets represents the fraction of the total awards. The average $\mathrm{DBE}, \mathrm{MBE}$, and WBE goals are calculated weighting by the dollar value of contract awards in the state. The DBE goal for the 1983-1987 period is obtained by taking the sum of a state's MBE and WBE goals. After 1987 , states set only an overall DBE goal. The last row, which indicates the number of state-months where the overall DBE goal changed, excludes changes in the total DBE goal between 1987 and 1988 due to the change in how that variable is defined. 
Table 2: DBE Goals by State

\begin{tabular}{|c|c|c|c|}
\hline & 1984 & 1991 & 1999 \\
\hline AK & 12 & 12 & 10 \\
\hline AL & 11 & 10 & 10 \\
\hline AR & 11 & 10 & 10 \\
\hline$A Z$ & 11.25 & 10 & 10 \\
\hline CA & 16 & 20 & 10 \\
\hline $\mathrm{CO}$ & 11 & 10 & 10 \\
\hline CT & 10.5 & 10 & 12 \\
\hline $\mathrm{DE}$ & 11 & 10 & 10 \\
\hline $\mathrm{FL}$ & 12 & 10 & 10 \\
\hline GA & 10.5 & 10 & 10 \\
\hline $\mathrm{HI}$ & 19.5 & 18 & 10 \\
\hline IA & 9.9 & 10 & 10 \\
\hline ID & 10.4 & 10 & 10 \\
\hline IL & 13.25 & 10 & 10 \\
\hline IN & 13 & 10 & 10 \\
\hline KS & 11.5 & 10 & 10 \\
\hline KY & 13 & 11 & 11.5 \\
\hline LA & 12 & 10 & 10 \\
\hline MA & 10.5 & 11 & 11 \\
\hline MD & 12 & 13 & 14 \\
\hline ME & 10.4 & 10 & 10 \\
\hline MI & 15 & 15 & 12 \\
\hline $\mathrm{MN}$ & 12 & 10 & 10 \\
\hline MO & 11 & 10 & 10 \\
\hline MS & 12 & 10 & 10 \\
\hline MT & 7.5 & 10 & 10 \\
\hline NC & 11 & 10 & 10 \\
\hline ND & 5.2 & 10 & 10 \\
\hline NE & 10.7 & 10 & 10 \\
\hline $\mathrm{NH}$ & 7.5 & 10 & 10 \\
\hline NJ & 14 & 10 & 16 \\
\hline NM & 10.4 & 11 & 13 \\
\hline NV & 11 & 10 & 10 \\
\hline NY & 12 & 17 & 13 \\
\hline $\mathrm{OH}$ & 13 & 10 & 10 \\
\hline OK & 13 & 10 & 10 \\
\hline OR & 11 & 12 & 12.5 \\
\hline PA & 12 & 10 & 10 \\
\hline RI & 10.5 & 10 & 10 \\
\hline SC & 10.15 & 10 & 10 \\
\hline SD & 14 & 10 & 10 \\
\hline TN & 10.6 & 10 & 10 \\
\hline $\mathrm{TX}$ & 10.5 & 10 & 15 \\
\hline UT & 10.1 & 10 & 10 \\
\hline VA & 11 & 12 & 10 \\
\hline VT & 8.5 & 10 & 10 \\
\hline WA & 13 & 16 & 16 \\
\hline WI & 13 & 10 & 10 \\
\hline WV & 13 & 10 & 10 \\
\hline WY & 5.5 & 10 & 10 \\
\hline
\end{tabular}




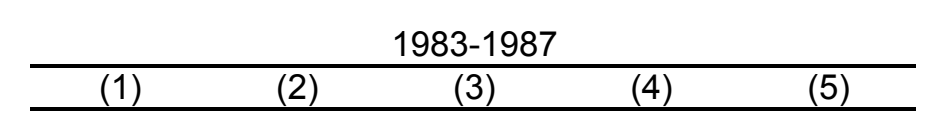

Dependent variable: $\triangle$ Percentage DBE Utilization

\begin{tabular}{|c|c|c|c|}
\hline$\triangle \mathrm{DBE}$ Goal \% & $\begin{array}{l}0.041 \\
(0.382)\end{array}$ & $\begin{array}{l}0.020 \\
(0.374)\end{array}$ & $\begin{array}{l}1.748 \\
(2.849)\end{array}$ \\
\hline$\Delta$ DBE Goal \% * Avg. Award/Commit Ratio & & & $\begin{array}{l}-1.666 \\
(2.716)\end{array}$ \\
\hline
\end{tabular}

$\triangle$ MBE Goal \%

$\triangle$ WBE Goal \%

\section{$\Delta$ Log GSP}

$\Delta$ Unemp. Rate

$\Delta$ Democratic governor

$\Delta$ Minority pop. share

Constant

N

R-squared

$\begin{array}{lllll} & & & & \\ & & & -0.302 & -0.306 \\ & & & (0.434) & (0.423) \\ & & & 0.673 & 0.616 \\ & & & (0.510) & (0.532) \\ & 0.166 & 0.167 & & 0.161 \\ & (0.084)^{*} & (0.084)^{*} & & (0.084)^{*} \\ & 0.004 & 0.004 & & 0.003 \\ & (0.006) & (0.007) & & (0.006) \\ & -0.008 & -0.008 & & -0.008 \\ & (0.009) & (0.009) & & (0.009) \\ & -2.713 & -2.855 & & -2.678 \\ 0.000 & (3.064) & (3.043) & & (3.003) \\ (0.007) & 0.031 & 0.030 & -0.000 & 0.033 \\ 200 & (0.029) & (0.029) & (0.007) & (0.027) \\ 0.11 & 200 & 200 & 200 & 200 \\ & 0.13 & 0.13 & 0.12 & 0.13\end{array}$

\begin{tabular}{lcc}
\multicolumn{3}{c}{$1988-1999$} \\
\hline$(6)$ & $(7)$ & $(8)$ \\
\hline
\end{tabular}

\begin{tabular}{lll}
0.405 & 0.396 & -0.567 \\
$(0.213)^{\star}$ & $(0.204)^{\star}$ & $(0.303)^{*}$ \\
& & 1.212 \\
& & $(0.433)^{\star \star \star}$ \\
& & \\
& & \\
& & \\
& 0.113 & 0.112 \\
& $(0.060)^{\star}$ & $(0.061)^{\star}$ \\
& -0.000 & -0.000 \\
& $(0.003)$ & $(0.003)$ \\
& 0.004 & 0.003 \\
& $(0.007)$ & $(0.007)$ \\
& & 1.295 \\
0.008 & -0.010 & $(0.791)$ \\
$(0.005)$ & $(0.011)$ & $(0.010$ \\
550 & 550 & 550 \\
0.13 & 0.13 & 0.14 \\
& & \\
\hline
\end{tabular}

$\left({ }^{* * *, * * *},{ }^{*}\right)$ indicates significance at the $99 \%, 95 \%$, and $90 \%$ level respectively. Robust standard errors corrected for clustering by state are in parentheses. Year effects are in the set of controls for each specification. 


\begin{tabular}{lcccc}
\multicolumn{6}{c}{$1983-1987$} \\
\hline$(1)$ & $(2)$ & $(3)$ & $(4)$ & $(5)$ \\
\hline
\end{tabular}

Dependent variable: $\triangle$ Percentage MBE Utilization
$\triangle \mathrm{DBE}$ Goal \%

$$
\begin{array}{lll}
0.529 & 0.517 & 1.975 \\
(0.192)^{* * *} & (0.196)^{* *} & (2.582) \\
& & -1.407 \\
& & (2.398)
\end{array}
$$
1.975
$\triangle \mathrm{DBE}$ Goal \% * Avg. Award/Commit Ratio

$\triangle$ MBE Goal \%

$\triangle$ WBE Goal \%

\section{$\Delta$ Log GSP}

$\Delta$ Unemp. Rate

$\Delta$ Democratic governor

$\Delta$ Minority pop. share

$\mathrm{N}$

R-squared

$\begin{array}{lllll} & & (2.398) & & \\ & & & 0.446 & 0.450 \\ & & & (0.187)^{\star \star} & (0.191)^{\star \star} \\ & & & 0.680 & 0.639 \\ & & (0.380)^{\star} & (0.393) \\ & 0.151 & 0.152 & & 0.150 \\ & (0.082)^{\star} & (0.082)^{\star} & & (0.081)^{\star} \\ & 0.005 & 0.005 & & 0.004 \\ & (0.006) & (0.006) & & (0.006) \\ & -0.004 & -0.004 & & -0.004 \\ & (0.007) & (0.007) & & (0.007) \\ & 0.018 & -0.102 & & 0.025 \\ -0.002 & (2.113) & (2.086) & & (2.110) \\ (0.006) & 0.025 & 0.023 & -0.002 & 0.025 \\ 200 & (0.024) & (0.025) & (0.006) & (0.023) \\ 0.15 & 200 & 200 & 200 & 200 \\ & 0.16 & 0.16 & 0.15 & 0.16\end{array}$

\begin{tabular}{lcc} 
& & \\
& $1988-1999$ & \\
\hline$(6)$ & $(7)$ & $(8)$ \\
\hline
\end{tabular}

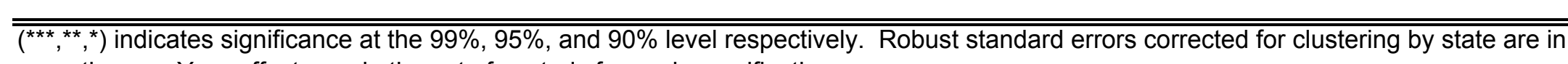
parentheses. Year effects are in the set of controls for each specification. 
Table 3c: State Regression of WBE Utilization Change on Change in Goals

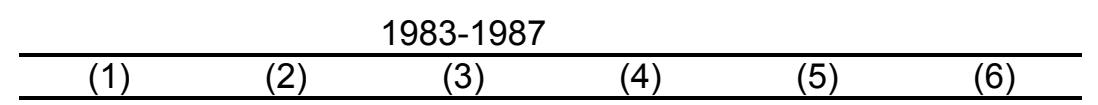

\begin{tabular}{lcc}
\multicolumn{3}{c}{$1988-1999$} \\
\hline$(7)$ & $(8)$ & $(9)$ \\
\hline
\end{tabular}

Dependent variable: $\triangle$ Percentage WBE Utilization

$\triangle$ DBE Goal \%

$\triangle \mathrm{DBE}$ Goal \% * Avg. Award/Commit Ratio

$\triangle$ MBE Goal \%

$\triangle$ MBE Goal \% * Avg. Award/Commit Ratio

$\triangle$ WBE Goal \%

$\triangle$ Log GSP

$\Delta$ Unemp. Rate

$\Delta$ Democratic governor

$\Delta$ Minority pop. share

Constant

$\mathrm{N}$

R-squared

$$
\begin{array}{lll}
-0.488 & -0.497 & -0.228 \\
(0.289)^{*} & (0.280)^{*} & (1.111) \\
& & -0.260 \\
& & (1.113)
\end{array}
$$

\begin{tabular}{|c|c|c|c|c|c|}
\hline & & & & .756 & 343 \\
\hline & & & $(0.413)^{*}$ & $(0.409)^{*}$ & $(1.487)$ \\
\hline & & & & & -2.524 \\
\hline & & & & & $(1.502)^{*}$ \\
\hline & & & -0.007 & -0.024 & 0.018 \\
\hline & & & $(0.249)$ & $(0.250)$ & $(0.232)$ \\
\hline & 0.015 & 0.015 & & 0.011 & 0.014 \\
\hline & $(0.031)$ & $(0.031)$ & & $(0.033)$ & $(0.033)$ \\
\hline & -0.001 & -0.001 & & -0.001 & -0.001 \\
\hline & (0.003) & $(0.003)$ & & $(0.003)$ & $(0.003)$ \\
\hline & -0.005 & -0.005 & & -0.004 & -0.004 \\
\hline & (0.004) & $(0.004)$ & & $(0.004)$ & $(0.004)$ \\
\hline & -2.731 & -2.753 & & -2.703 & -3.035 \\
\hline & (2.405) & $(2.414)$ & & $(2.382)$ & $(2.429)$ \\
\hline 0.002 & 0.007 & 0.007 & 0.002 & 0.008 & 0.009 \\
\hline$(0.004)$ & $(0.012)$ & $(0.012)$ & $(0.004)$ & $(0.011)$ & $(0.011)$ \\
\hline 200 & 200 & 200 & 200 & 200 & 200 \\
\hline 0.04 & 0.05 & 0.05 & 0.06 & 0.07 & 0.08 \\
\hline
\end{tabular}

$\begin{array}{lll}0.048 & 0.043 & -0.105 \\ (0.092) & (0.092) & (0.157) \\ & & 0.187 \\ & & (0.208)\end{array}$

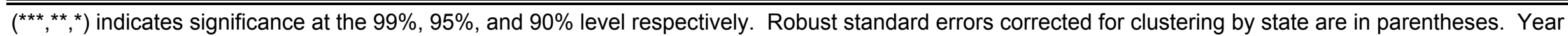
effects are in the set of controls for each specification. 
Table 4: Effect of Changing State DBE Goals by Likelihood of Goals Binding

All state months

Prior year's DBE attainment:

within $3 \%$ of goal

greater than 3\% away from goal

\begin{tabular}{cc}
$\frac{2}{2}$ DBE Utilization \\
\hline$<1988$ & $>1988$ \\
0.020 & 0.396 \\
$(0.374)$ & $(0.204)^{\star}$
\end{tabular}

\begin{tabular}{cc}
$\frac{2}{2}$ MBE Utilization \\
\hline$<1988$ & $>1988$ \\
0.517 & 0.353 \\
$(0.196)^{\star \star}$ & $(0.166)^{\star \star}$
\end{tabular}

\begin{tabular}{cc}
$\frac{2}{2}$ WBE Utilization \\
\hline$<1988$ & $>1988$ \\
-0.497 & 0.043 \\
$(0.280)^{\star}$ & $(0.092)$
\end{tabular}

\begin{tabular}{lcc} 
& & \\
within 3\% of goal & -0.264 & 0.588 \\
& $(0.280)$ & $(0.297)^{\star}$ \\
greater than 3\% away from goal & {$[89]$} & {$[290]$} \\
& 0.123 & 0.312 \\
& $(0.506)$ & $(0.216)$ \\
\hline
\end{tabular}

$(* \star *, * *, *)$ indicates significance at the 99\%, 95\%, and 90\% level respectively. Robust stanc

$\begin{array}{cc}-0.142 & 0.480 \\ (0.394) & (0.264)^{\star} \\ {[89]} & {[290]} \\ 0.724 & 0.300 \\ (0.255)^{\star \star \star} & (0.203) \\ {[111]} & {[260]}\end{array}$

-0.122
$(0.195)$
$[89]$
-0.600
$(0.370)$
$[111]$

0.109

(0.283)

[290]

0.012

$(0.095)$

[260]

. given in the column heading. The first row restates the results without limiting the sample, as reported in Tables $3 a-3 c$. In the specifications presented in the following rows, the sample is restricted first to cases where the state's utilization of DBEs was within three percentage points of the DBE goal and subsequently to cases where state DBE utilization was further than three percentage points away from the DBE goal. Each specification contains the full set of controls described in Tables 3a-3c. 


\begin{tabular}{|c|c|c|c|c|}
\hline & \multicolumn{4}{|c|}{ DBE Goal } \\
\hline & $0 \%$ & $1-10 \%$ & $10-20 \%$ & Overall \\
\hline & $(1)$ & $(2)$ & (3) & $(4)$ \\
\hline Winning bid (000s) & $\begin{array}{c}466.6 \\
(1095.8)\end{array}$ & $\begin{array}{c}1437 \\
(1817.3)\end{array}$ & $\begin{array}{c}4088.7 \\
(7230.7)\end{array}$ & $\begin{array}{c}2611.8 \\
(5214.2)\end{array}$ \\
\hline Final Payment (000s) & $\begin{array}{c}541.4 \\
(1217.0)\end{array}$ & $\begin{array}{c}1549.9 \\
(1995.1)\end{array}$ & $\begin{array}{c}4463.2 \\
(8074.4)\end{array}$ & $\begin{array}{c}2841.8 \\
(5808.7)\end{array}$ \\
\hline DBE Goal & 0 & $\begin{array}{l}7.18 \% \\
(1.41)\end{array}$ & $\begin{array}{c}12.90 \% \\
(2.23)\end{array}$ & $\begin{array}{c}11.26 \% \\
(3.49)\end{array}$ \\
\hline DBE Utilization (000s) & $\begin{array}{c}34.9 \\
(85.7) \\
{[6.4 \%]}\end{array}$ & $\begin{array}{c}160.6 \\
(315.8) \\
{[10.4 \%]}\end{array}$ & $\begin{array}{c}601.7 \\
(1504.6) \\
{[13.5 \%]}\end{array}$ & $\begin{array}{c}357.8 \\
(1059.9) \\
{[12.6 \%]}\end{array}$ \\
\hline Engineer's Estimate (000s) & $\begin{array}{c}597.3 \\
(1587.9)\end{array}$ & $\begin{array}{c}1615.7 \\
(2040.0)\end{array}$ & $\begin{array}{c}4450.9 \\
(8067.7)\end{array}$ & $\begin{array}{c}2870.7 \\
(5805.7)\end{array}$ \\
\hline Workdays & $\begin{array}{c}136.7 \\
(288.1)\end{array}$ & $\begin{array}{c}104.6 \\
(112.6)\end{array}$ & $\begin{array}{c}194.2 \\
(206.2)\end{array}$ & $\begin{array}{c}147.5 \\
(176.2)\end{array}$ \\
\hline Number of Items & $\begin{array}{c}18.1 \\
(11.4)\end{array}$ & $\begin{array}{c}29.9 \\
(18.0)\end{array}$ & $\begin{array}{c}56.6 \\
(43.2)\end{array}$ & $\begin{array}{c}41.7 \\
(34.7)\end{array}$ \\
\hline Number of subcontractors & $\begin{array}{c}2.69 \\
(2.08)\end{array}$ & $\begin{array}{c}4.39 \\
(2.70)\end{array}$ & $\begin{array}{c}6.52 \\
(3.49)\end{array}$ & $\begin{array}{c}5.32 \\
(3.27)\end{array}$ \\
\hline $\mathrm{N}$ & 39 & 658 & 584 & 1293 \\
\hline
\end{tabular}

The DBE goal is weighted by the engineer's estimate when calculating the average. Final payment represents the payments made to the contractor inclusive of change orders. The numbers in brackets represent the percent of final payment to the contractor that is awarded to DBEs. 
Table 6: DBE Utilization and Goals Across Projects

\begin{tabular}{|c|c|c|c|c|c|c|}
\hline & \multicolumn{2}{|c|}{ OLS } & \multicolumn{2}{|c|}{ First Stage } & \multicolumn{2}{|c|}{ IV } \\
\hline & $(1)$ & $(2)$ & (3) & (4) & $(5)$ & (6) \\
\hline DBE Goal & $\begin{array}{c}0.398 \\
(0.065)^{\star \star \star}\end{array}$ & $\begin{array}{c}0.409 \\
(0.120)^{\star \star \star}\end{array}$ & & & $\begin{array}{c}0.538 \\
(0.186)^{\star \star \star}\end{array}$ & $\begin{array}{c}0.535 \\
(0.289)^{*}\end{array}$ \\
\hline Other district goal & & & $\begin{array}{c}0.501 \\
(0.047)^{\star \star \star}\end{array}$ & $\begin{array}{c}0.384 \\
(0.058)^{\star \star \star}\end{array}$ & & \\
\hline Controls & N & Y & $\mathrm{N}$ & $Y$ & $\mathrm{~N}$ & Y \\
\hline R2 & 0.04 & 0.10 & 0.084 & 0.402 & & \\
\hline $\mathrm{N}$ & 1264 & 1263 & 1264 & 1263 & 1264 & 1263 \\
\hline
\end{tabular}

$(\star \star \star *, * \star, *)$ indicates significance at the 99\%, 95\%, and 90\% level respectively. Robust standard errors corrected for clustering by state are in parentheses. Controls in columns (2), (4), and (6) include quadratic in number of items and number of workdays, the log of the engineer's estimate, month effects, work classification dummies, and a quadratic time trend. The dependent variable in columns (1), (2), (5), and (6) is DBE utilization as a fraction of payments to the contractor. Columns (3) and (4) present the first stage estimates with the DBE goal as the dependent variable. 